\title{
Elevated IgM levels as a marker for a unique phenotype in patients with Ataxia telangiectasia
}

\author{
Alexander Krauthammer ${ }^{1,6^{*}} \mathbb{D}$, Avishay Lahad ${ }^{1,2}$, Lior Goldberg ${ }^{1,6}$, Ifat Sarouk ${ }^{1,3}$, Batia Weiss ${ }^{2,6}$, Raz Somech ${ }^{1,6}$, \\ Michalle Soudack ${ }^{1,4}$ and Itai M. Pessach ${ }^{5,6}$
}

\begin{abstract}
Background: Ataxia telangiectasia (AT) is a rare, multi-systemic, genetic disorder. Mutations in the ATM gene cause dysfunction in cell-cycle, apoptosis and V (D) J recombination leading to neurodegeneration, cellular, humoral immunodeficiencies and predisposition to malignancies. Previous studies have suggested that a sub-group of AT patients with elevated IgM levels have a distinct and more severe phenotype. In the current study we aimed to better characterize this group of patients.

Methods: We performed a retrospective review of 46 patient records, followed from January 1986 to January 2015 at the Israeli National AT Center. Demographic, clinical, radiological, laboratory data was reviewed and compared between AT patients with elevated IgM levels (ElgM) and patients with normal lgM levels (NIgM).

Results: 15/46(32.6\%) patients had significantly elevated lgM levels. This group had a unique phenotype characterized mainly by increased risk of infection and early mortality. Colonization of lower respiratory tract with Mycobacterium gordonae and Pseudomonas aeruginosa as well as viral skin infections were more frequent in ElgM patients. Patients with NlgM had a significantly longer survival as compared to patients with ElgM but had an increased incidence of fatty liver or cirrhosis. T-cell recombination excision circles and kappa-deleting element recombination circle levels were significantly lower in the ElgM group, suggesting an abnormal class switching in this group.
\end{abstract}

Conclusions: ElgM in AT patients are indicative of a more severe phenotype that probably results from a specific immune dysfunction. ElgM in AT should be considered a unique AT phenotype that may require different management.

Keywords: AT, Class switching, Complications, Elevated IgM, Immunoglobulins, Lung functions, Phenotype

\section{Background}

Ataxia telangiectasia (AT) is a rare multi-systemic disorder. Mutations in the ATM gene causes dysfunction in cell cycle, apoptosis, DNA repair and V (D) J recombination [1-3]. Neurodegeneration, predisposition to malignancies as well as cellular and humoral immunodeficiency are the main complications [4]. Patients that have no ATM kinase activity are highly affected, while those with residual kinase activity usually present less severe neurologic disabilities and milder immune deficiency [5-7].

\footnotetext{
* Correspondence: krautalex@gmail.com

'Department of Pediatrics, The Edmond and Lily Safra Children's Hospital, 52625 Tel- Hashomer, Israel

${ }^{6}$ Sackler Faculty of Medicine, Tel-Aviv University, Tel-Aviv, Israel

Full list of author information is available at the end of the article
}

Immunodeficiency is present in up to $70 \%$ of AT patients. Embryonic or absent thymus, premature ageing of the immune system, abnormal $\mathrm{T}$ and $\mathrm{B}$ cell neogenesis and abnormal surface $\mathrm{T}$ cell receptor expression were shown to play a crucial role in AT associated immunodeficiency $[2,8]$. The humoral immunodeficiency in AT includes $\operatorname{IgG} 2$ and IgG4 deficiencies, low or absent IgA and IgE and abnormal humoral response to vaccination [2]. Cellular immunodeficiency includes leukopenia, low CD4 + T cell counts and impaired lymphoprolifirative responses to antigens and mitogens [9]. AT patients often suffer from recurrent lower respiratory tract infections with subsequent pulmonary insufficiency resulting from a combination of immunodeficiency, recurrent aspirations, decreased mobilization and abnormal muscle tone $[3,10,11]$. Poor growth,

(c) The Author(s). 2018 Open Access This article is distributed under the terms of the Creative Commons Attribution 4.0 International License (http://creativecommons.org/licenses/by/4.0/), which permits unrestricted use, distribution, and reproduction in any medium, provided you give appropriate credit to the original author(s) and the source, provide a link to the Creative Commons license, and indicate if changes were made. The Creative Commons Public Domain Dedication waiver (http://creativecommons.org/publicdomain/zero/1.0/) applies to the data made available in this article, unless otherwise stated. 
liver abnormalities and insulin resistant diabetes are also a part of the AT phenotype [12-14].

Several reports have suggested that a subgroup of patients with AT present with higher levels of IgM that might be associated with a more severe phenotype [15-19]. A more recent study describing a cohort of 61 patients, concluded that patients with Hyper IgM phenotype and IgG2 deficiency showed decreased survival compared to AT patients with NIgM [20].

The aim of the present study was to better characterize the subgroup of AT patients with EIgM. We hypothesized that patients with elevated IgM levels may represent a separate phenotype similar to that seen in Hyper IgM syndrome [21-23], leading to more severe infectious, neoplastic and pulmonary morbidity and eventually shorter survival.

\section{Methods}

\section{Patients}

The Israeli National Clinical Center for Ataxia Telangiectasia at the Edmond and Lily Safra Children's Hospital, Sheba Medical Center cares for most of the Ataxia Telangiectasia patients in Israel. We retrospectively reviewed the medical records of 53 AT patients followed at the Center between January 1st, 1986 and January 31, 2015. Forty-six patients were enrolled in this study, and 7 were excluded due to lack of sufficient data. The diagnosis of AT was based on a well-established set of criteria, as previously published [14]. Briefly, in addition to a distinctive clinical presentation suggestive of AT one of the following was required: mutations in the ATM gene, homozygous or compound heterozygous $(N=34)$, abnormal signal of the ATM protein on western blot $(N=12)$, or immune deficiency/chromosomal breakage/T cell malignancy in the presence of increased $\alpha$-fetoprotein and cerebellar atrophy on magnetic resonance imaging (MRI) $(N=3)$. A specialized multidisciplinary team including an immunologist, pulmonologist and gastroenterologist evaluated all the patients every 6 month, or more frequently if required.

Patients with IgM levels at least 20\% higher than the upper normal limit (Additional file 1: Table S1), on at least two separated occasions, were categorized as "elevated IgM" (EIgM). Clinical characteristics, disease course and complications were compared between EIgM patients and patients with NIgM. Immune system function, pulmonary function, infections, liver enzymes and predisposition to cancer were analyzed and results were compared between the two groups.

The study was approved by the Sheba Medical Center Institutional review board (SMC-IRB). The data retrieved from all patient charts was coded and de identified prior to analysis, hence the need for written consent was formally waved by the SMC-IRB.

\section{Infections and immune function}

We retrospectively reviewed all the available laboratory data of the immune system from patient's charts, including complete blood counts, immunoglobulin levels and distribution, T-cell recombination excision circles (TREC) and kappa-deleting element recombination circle (KREC) levels as well as $\mathrm{T}$ and $\mathrm{B}$ cell subpopulations. Information regarding various infections was extracted from the patient's medical records and was further defined as viral, bacterial, fungal or parasitic. Quantification of TRECs and KRECs were determined by real-time quantitative (RQ)-PCR as was previously described [24, 25]. Age-matched healthy individuals were used as controls. Each experiment was performed in triplicate, and the threshold for Ct determination was positioned at the same level each time.

\section{Respiratory functions tests - Spirometry}

In accordance with the AT clinic policy each patient had spirometry tests results recorded at least once. Lung function measurements including forced vital capacity (FVC \%) and forced expiratory volume (FEV 1\%) were recorded, and the best of three results was included in the study.

\section{Serum liver enzyme levels}

Alanine transaminase (ALT) and aspartate aminotransferase (AST) levels were measured. Levels exceeding at least 1.5 times the upper limit of normal (ULN) on 3 or more separate occasions were considered abnormal, after extensive workup to exclude possible etiologies for LFT elevation.

\section{Imaging studies}

Chest $\mathrm{X}$ ray, abdominal sonography and other imaging studies were performed as part of the ongoing care of the patients. All radiographs were obtained with computed radiography. All studies were evaluated by a pediatric radiologists on a PACS workstation (Easyvision, Sectra Imtec AB, Linköping, Sweden) using Totuko monitors (Totuko Electric co., ltd., Tokyo, Japan).

\section{Statistical analysis}

All measured variables and derived parameters were tabulated by descriptive statistics. Pearson correlation coefficients were calculated for testing the relation between two continuous parameters. Student's T-test was applied for testing the statistical significance of the difference between means in continuous variables. All tests applied were two-tailed, and a $p$ value of $5 \%$ or less was considered statistically significant. Survival was assessed using the Kaplan-Meier method. Differences in survival outcomes were evaluated with the log-rank test. Statistical analysis was done using the IBM ${ }^{\mathrm{Im}} \mathrm{SPSS}^{\mathrm{Tm}}$ Version 21 software, New York, USA and Excel 2013 program. 


\section{Results}

Medical charts of 46 AT patients (24 males), age $14.6 \pm 4.6$ years, were reviewed. The average age of AT diagnosis was $4.3 \pm 3.6$ years, and average duration of follow-up was $8.3 \pm 4$ years (median 8 years, range 0.5-17 years). The diagnosis of AT was based on detection of ATM mutation in 35/46 (76\%) of patients, low ATM on western blot in $9 / 46$ (19.6\%) and clinically in $2 / 46(4.4 \%)$ of patients.

Out of 46 patients with available IgM values, 15/46(33\%) had EIgM with average serum IgM levels of $356 \pm 200 \mathrm{mg} / \mathrm{dl}$ that were statistically higher than the average IgM levels seen in the NIgM group $(129.2 \pm 56.5 \mathrm{mg} / \mathrm{dl}, p<0.001)$. Eight of 15 patients (53\%) with EIgM, were males. There was no significant difference in average age between the EIgM group and the NIgM group $(15.2 \pm 2.3$ years vs $14.4 \pm 5.1$ years, $p=0.32$, respectively). Clinical and demographic characteristics of both groups are presented in Table 1.

\section{Complications \\ Infections}

During the follow-up period, 88 infectious episodes were documented in all patients. Bacterial infections were the most frequent $66 / 88$ (75\%), followed by fungal $12 / 88$ (13.6\%), viral $9 / 88(10.2 \%)$ and parasitic $1 / 88(1.2 \%)$ infections. AT patients suffered mainly from infections of the respiratory tract, as was previously described [18-20]. Chronic pulmonary colonization with Mycobacterium gordonae and Pseudomonas aeruginosa were significantly more frequent in the EIgM patients than in patients with NIgM, 4/15(27\%) vs $1 / 31(3 \%), p<0.017$ and $7 / 15(47 \%)$ vs $6 / 31(19.4 \%), p=0.05$, respectfully. The incidence of infections with Streptococcus pneumonia was similar in both groups. Colonization of the lower respiratory tract with Trichoderma sp., Candida sp. and Aspergillus niger trended towards higher frequency in EIgM patients, but this trend did not reach statistical significance.

Table 1 Clinical characteristics of ElgM and NlgM patients

\begin{tabular}{llll}
\hline Parameter $^{\mathrm{a}}$ & $\mathrm{ElgM}$ & $\mathrm{NlgM}$ & $\mathrm{p}$ \\
\hline $\mathrm{N}$ & $15 / 46(32.6)$ & $31 / 46(67.4)$ & $\mathrm{N} / \mathrm{A}$ \\
Gender, male & $8 / 15(53)$ & $16 / 31(52)$ & $p=0.9$ \\
Average age, years & $15.2 \pm 2.8$ & $14.3 \pm 5.2$ & $p=0.35$ \\
$\begin{array}{l}\text { Age of elevated IgM } \\
\text { detection, years }\end{array}$ & $9.3 \pm 4.2$ & $\mathrm{~N} / \mathrm{A}$ & $\mathrm{N} / \mathrm{A}$ \\
$\begin{array}{l}\text { IgM levels (mg/dl) } \\
\begin{array}{l}\text { Deceased N/Total in } \\
\text { the group }\end{array}\end{array}$ & $356 \pm 200$ & $129.2 \pm 56.5$ & $p<0.001$ \\
Age at demise, years & $13.7 \pm 4.2$ & $18.3 \pm 6.3$ & $p=0.05$ \\
\hline
\end{tabular}

N/A Not Applicable

${ }^{a}$ Continuous variables are presented as mean \pm SD. Categorical variables are presented as $\mathrm{N}(\%)$
Human Papilloma virus skin infections were observed in 2 out of 15 EIgM patients (13.3\%) while none were seen in the 31 NIgM patients $(p=0.04)$. However, skin infections with HSV and VZV were similarly frequent in both groups (1/15 vs 0/31patients with HSV skin infections and $2 / 15$ vs $2 / 31$ VZV infected patients, respectively). Systemic infections with $E B V$ and $C M V$ were rare and were only observed in 2 patients with NIgM. Herpes simplex virus type 1 (HSV1) encephalitis and severe disseminated infection with Varicella zoster virus (VZV) were seen in one patient NIgM and one patient with EIgM. Skin infection related to vaccinations were not observed.

\section{Pulmonary disease}

In light of the higher frequency of chronic pulmonary infection in the EIgM group, we expected a more severe pattern of chronic pulmonary disease in this group. Information regarding pulmonary functions was available for $23 / 31(74 \%)$ patients with NIgM, aged $12.2 \pm 5.4$ years and 10/15(67\%) of patients with EIgM, aged 12.2 \pm 2.5 years, at the time of observation. Average FEV1 and FVC measurements were similar between the EIgM and NIgM groups $51.1 \pm 20.1$ vs $41.8 \pm 10.6, p=0.12$ and $42.7 \pm 15.3$ vs $36.5 \pm 7.8, p=0.13$, respectively. During the follow up period, 329 chest X-ray examinations (CXR) were performed with an average of $1.2 \pm 2.5 \mathrm{x}$-rays per patient per year of follow up in patients with NIgM vs $1.1 \pm 2.1 \mathrm{x}$-rays per patient per year of follow up in patients with EIgM. All CXRs were re-evaluated by a pediatric radiologist for the presence of bronchiectasis in both groups, however, no significant difference was found. Bronchiectasis was present in $6 / 31(19 \%)$ of the patients with NIgM compared to $3 / 15(20 \%)$ of the patients in the EIgM group, $p=0.87$.

\section{Liver function tests (LFTs)}

LFTs were available in $41(89.1 \%)$ patients. There was no difference in the number of the EIgM and NIgM patients with elevated LFT (9/13(69\%) vs13/28(46.4\%), respectively, $p=0.2$ ). Neither average AST nor ALT were significantly different between the groups (49.8 \pm 10.6 vs $48.1 \pm 27.8 \mathrm{IU} / \mathrm{L}, p=0.4$ and $33.7 \pm 10$ vs $47.2 \pm 32.7 \mathrm{IU} / \mathrm{L}$, $p=0.08$, respectively). Abdominal sonography was performed in 14/15 (93.3\%) patients with EIgM and 26/ $31(84 \%)$ with NIgM). Interestingly, none of the EIgM patients developed signs of fatty liver or cirrhosis, while 9 of the 26 (34.6\%) patients with NIgM levels showed these liver abnormalities, $p<0.01$. Average alpha-fetoprotein (AFP) levels were similarly elevated in both groups $(286.5 \pm 198 \mathrm{ng} / \mathrm{ml}$ in EIgM patients vs $251 \pm 157 \mathrm{ng} / \mathrm{ml}$ in NIgM patients, $p=0.55$ ).

\section{Cancer}

Cancer remained one of the main complications and leading causes of death among our patients. Three of 15 (20\%) 
EIgM patients had cancer compared to 9 of 31(29\%) patients with NIgM, $p=0.5$. Lymphoma, acute lymphoblastic leukemia all of them T-cell (T-ALL) and solid tumors were the leading cancers seen in our cohort (8/46(17.4\%), 4/46(8.7\%) and 5/46(10.9\%), respectively). These findings are similar to those reported in previously published cohorts $[12,26]$. The average age of cancer diagnosis was $10.7 \pm 3.3$ years in the EIgM group vs $11.2 \pm 6.2$ years, in the NIgM patients. Several patients were diagnosed with more than one type of cancer.

\section{Mortality and survival analysis}

During the 29 years of follow up 17(37\%) patients died. The average age of death was $15.4 \pm 6.3$ for the entire cohort. The oldest patient alive at the time of the end of the study was 25.1 years old. The longest survival observed was 27.1 years. These results are similar to the survival observed in previously published cohorts [20, 26]. Patients with NIgM levels had significantly longer survival compared to patients with $\operatorname{EIgM}(\mathrm{z}=2.31, p=0.05)$ (Fig. 1). The average age of death was $13.4 \pm 4.2$ years for the EIgM group vs $18.3 \pm 6.3$ years, $(p=0.042)$ in the NIgM patients.

\section{Immunologic findings}

As part of the routine follow-up of AT patients, a broad immunological evaluation was performed in most patients

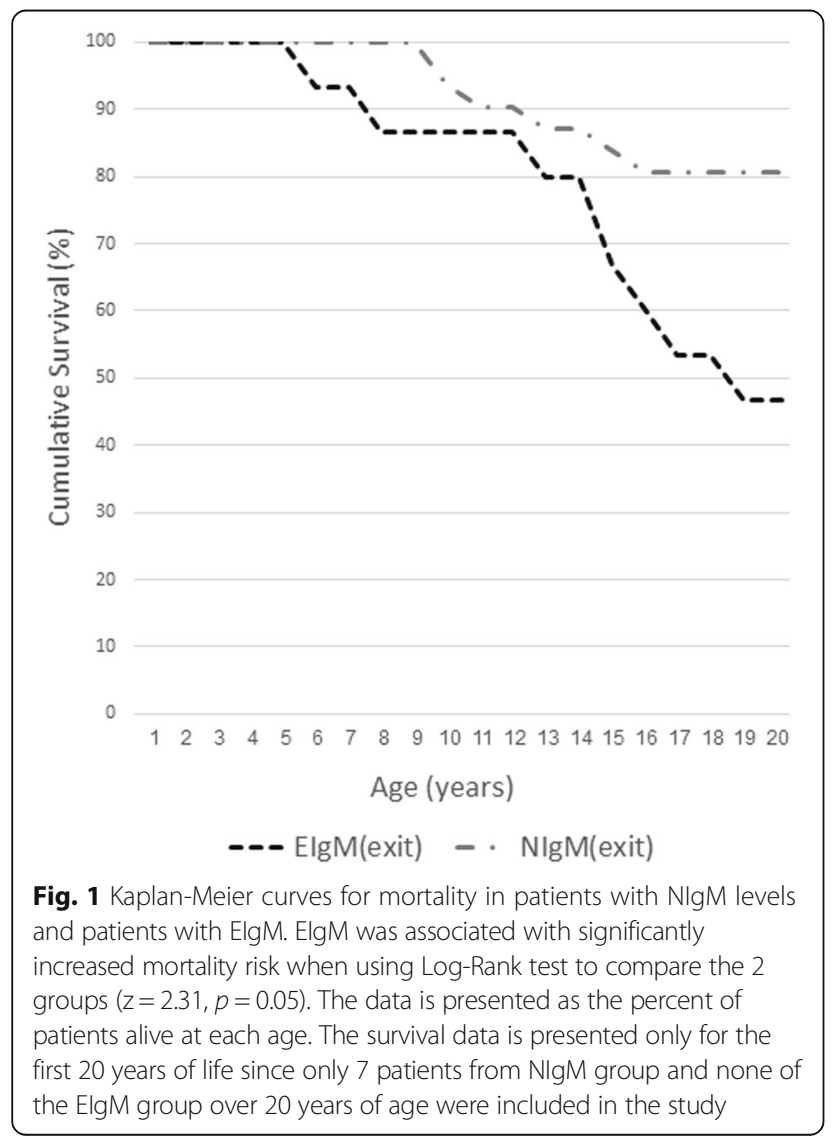

in our cohort. The baseline evaluation included complete blood count, immunoglobulin levels, T, B lymphocyte and NK cell sub-populations and basic complement studies. CD20+ lymphocytes and CD3+ lymphocytes were decreased in $8 / 46(17.4 \%)$ and $15 / 46(32.6 \%)$ of the patients, respectively, while $7 / 32(21.9 \%)$ of the patients had reduced lymphoproliferative responses. We did not observe any significant difference in lymphocyte subpopulations and lymphoproliferative responses between EIgM and NIgM patients. There was no significant difference in complement levels or in the ability to mount an adequate response to vaccination (data not shown).

The need for immunoglobulin replacement therapy with IVIG trended to be more frequent in the group of patients with EIgM in which 10/13(77\%) received IVIG as compared to $14 / 27(52 \%),(p=0.13)$ in the NIgM group.

Previous studies on this cohort of patients have demonstrated that AT patients have low T-cell recombination excision circles (TREC) and kappa-deleting element recombination circle (KREC) levels with abnormal TCR-V $\beta$ repertoires [8].

Interestingly, despite the similar amounts of CD3+ and CD20+ cells in both groups, we observed a significantly lower KREK-CJ and TREK levels and a trend towards lower KREK-SJ levels in the EIgM group compared to the levels in normal IgM patients (Table 2).

Table 2 Immunological features of ElgM and NIgM patients

\begin{tabular}{|c|c|c|c|}
\hline Parameter $^{a}$ & $\begin{array}{l}\text { ElgM } \\
N=15\end{array}$ & $\begin{array}{l}\mathrm{NlgM} \\
N=31\end{array}$ & $\mathrm{p}$ \\
\hline$\overline{W B C}(\mathrm{~K} / \mathrm{mL})$ & $8.8 \pm 1.6$ & $8 \pm 2.9$ & $p=0.16$ \\
\hline ANC (K/ml) & $5.6 \pm 1.3$ & $5.2 \pm 2.5$ & $p=0.3$ \\
\hline $\mathrm{ALC}(\mathrm{K} / \mathrm{ml})$ & $1.7 \pm 0.5$ & $1.9 \pm 0.8$ & $p=0.25$ \\
\hline $\mathrm{CD} 3+(\mathrm{K} / \mathrm{ml})$ & $1042 \pm 526$ & $959 \pm 511$ & $p=0.33$ \\
\hline $\mathrm{CD} 4+(\mathrm{K} / \mathrm{ml})$ & $466 \pm 236$ & $839 \pm 1797$ & $p=0.25$ \\
\hline $\mathrm{CD} 8+(\mathrm{K} / \mathrm{ml})$ & $597 \pm 433$ & $443 \pm 247$ & $p=0.09$ \\
\hline $\mathrm{CD} 20+(\mathrm{K} / \mathrm{ml})$ & $145 \pm 67$ & $167 \pm 185$ & $p=0.36$ \\
\hline CD56+ (K/ml) & $26 \pm 10$ & $23 \pm 10.7$ & $p=0.24$ \\
\hline Patients treated with IVIG & 10/13(77) & $14 / 27(52)$ & $p=0.13$ \\
\hline Age at IVIG initiation (years) & $9.4 \pm 5.7$ & $6.6 \pm 3.7$ & $p=0.09$ \\
\hline Average $\lg \mathrm{A}(\mathrm{mg} / \mathrm{dL})$ & $82 \pm 97$ & $59.5 \pm 81$ & $p=0.22$ \\
\hline $\mathrm{C} 3(\mathrm{mg} / \mathrm{dL})$ & $146 \pm 30.4$ & $144.1 \pm 11.3$ & $p=0.46$ \\
\hline $\mathrm{C} 4(\mathrm{mg} / \mathrm{dL})$ & $27 \pm 8$ & $37.4 \pm 1.8$ & $p=0.06$ \\
\hline KREC-CJ & $732 \pm 390$ & $2568 \pm 3115$ & $p=0.033$ \\
\hline KREC-SJ & $22 \pm 17$ & $112 \pm 199$ & $p=0.08$ \\
\hline TREC & $13.9 \pm 8.2$ & $64.2 \pm 93.5$ & $p=0.046$ \\
\hline Normal lymphocyte proliferation & $6 / 9(67)$ & 19/23(83) & $p=0.33$ \\
\hline
\end{tabular}

WBC white blood cells, ANC Absolute neutrophil count, $A L C$ absolute lymphocyte count, IVIg Intravenous immune globulin, C Complement, NK Natural Killer cell, TREC T cell receptor excision circle, KREC kappa-deleting recombination excision circles (CJ $\psi \mathrm{J}$ a coding joint, $S J \psi J \mathrm{Ja} \mathrm{signal}$ joint) ${ }^{a}$ Continuous variables are presented as mean \pm SD. Categorical variables are presented as $\mathrm{N}(\%)$ 


\section{Discussion}

AT is a rare, autosomal recessive, progressive, multi systemic disease with well described cellular and humoral immunodeficiency [4]. Hypogammaglobulinemia with low IgG, IgA and IgE levels, is a frequent presentation of this disease [27]. On the other hand, different studies have shown variability in IgM levels in these patients with normal or mildly elevated levels in up to $60 \%$ of the patients [19]. As a result, some AT patients are initially misdiagnosed with Hyper IgM syndrome, while the definitive AT diagnosis is made later by genetic analysis or western blot, following the accumulation of clinical characteristics indicative of AT. Recent studies advocated that elevated IgM levels should be included in the diagnostic criteria for AT suggesting that patients with this presentation might have a worse prognosis $[19,20]$.

In our cohort, 15 of 46 patients (32.6\%) had elevated IgM levels, a slightly higher fraction as compared to previously published cohorts [19, 20, 28].

We have observed that AT patients with elevated IgM levels are more prone to colonization of the lower respiratory tract with pathogenic gram-negative bacteria as well as to higher frequency of viral skin infections, a presentation similar to that seen in other Hyper IgM phenotypes [29].

Despite these findings, we were not able to demonstrate a significant difference in pulmonary function between AT patients with normal or elevated IgM levels. This may have resulted from the fact that lung function testing in our cohort was done at a relatively young age, before recurrent lung infections had inflicted significant accumulative damage to the lung tissue.

Predisposition of AT patients to hepatic disease, which in some cases progresses to non-alcoholic steatohepatitis (NASH) and even cirrhosis with portal hypertension, was recently described [14]. In the current study, we observed that patients with elevated IgM levels did not present this phenotype. The progression of liver disease and insulin resistance in AT patients were recently shown to be age dependent [30]. Thus, it is possible that the shortened survival in the EIgM group paradoxically results in less apparent liver involvement, which might have developed, should these patients have survived longer. On the other hand, this could also be a distinctive clinical characteristic of the EIgM group. Further studies are needed to better illuminate this question.

Increased risk of developing cancer is a well-known feature of $\mathrm{AT}[12,26,31]$. In contrast to previous reports, we did not observe an increased risk of malignancy in the group of EIgM patients.

Recent studies have investigated class switch recombination (CSR) as a critical mechanism in lymphocyte maturation in AT, reporting abnormal class switching in AT patients with high IgM levels [20, 28, 32]. The lower levels of KREC and TREC levels seen in the EIgM group in our cohort further supports these findings.

\section{Conclusions}

Taken together, our findings further support previous reports suggesting that AT patients with elevated IgM levels represent a distinct group with a severe disease phenotype and worse prognosis resulting from a prominent CSR defect.

Further larger prospective studies in this subpopulation would be needed to establish a tailored management approach including close surveillance with early and aggressive treatment.

\section{Additional file}

Additional file 1: Table S1. The reference range of immunoglobulin $\mathrm{M}(\mathrm{IgM})$ based on age* (DOCX $13 \mathrm{~kb})$

\section{Abbreviations}

AFP: Alfa fetoprotein; AT: Ataxia telangiectasia; ATM: Ataxia telangiectasia mutated; BMI: body mass index; CMV: Cytomegalovirus; CSR: Class switch recombination; EBV: Epstein-Barr virus; ElgM: Elevated lgM; FEV1: Forced expiratory volume (1 sec); FVC: Forced vital capacity; HSV1: Herpes simplex virus type 1; IgM: Immunoglobulin M; IVIG: Intravenous immunoglobulin; KREC: Kappa recombination excision circles; NASH: Nonalcoholic

steatohepatitis; NIgM: Normal IgM; NK: Natural killer cells; PEG: Percutaneous gastrostomy; TCR: T cell receptor; TREC: T-cell receptor excision circles;

VZV: Varicella zoster virus

Availability of data and materials

The datasets used and analyzed during the current study are available from the corresponding author on reasonable request.

\section{Authors' contributions}

AK conceptualized and designed the study, drafted the initial manuscript, and approved the final manuscript as submitted. AL, LG, BW, IS, RS and MS carried out the initial analyses, reviewed and revised the manuscript. IMP designed the data collection instruments, coordinated and supervised data collection and critically reviewed the manuscript. All authors edited and approved the final manuscript as submitted.

Ethics approval and consent to participate

The above study was reviewed and approved by the Sheba Medical Center Institutional review board (SMC-IRB), (reference 2867-15-SMC). The data retrieved from all patient charts was coded and de identified prior to analysis. Since this study is a retrospective chart review study the need for written consent was formally waved by the SMC-IRB.

\section{Competing interests}

The authors declare that they have no competing interests.

\section{Publisher's Note}

Springer Nature remains neutral with regard to jurisdictional claims in published maps and institutional affiliations.

\section{Author details}

${ }^{1}$ Department of Pediatrics, The Edmond and Lily Safra Children's Hospital, 52625 Tel- Hashomer, Israel. ${ }^{2}$ Pediatric Gastroenterology Unit, The Edmond and Lily Safra Children's Hospital, Tel- Hashomer, Israel. ${ }^{3}$ Pediatric Pulmonary Unit, The Edmond and Lily Safra Children's Hospital, Tel- Hashomer, Israel. ${ }^{4}$ Pediatric Radiology Unit, The Edmond and Lily Safra Children's Hospital, Tel- Hashomer, Israel. ${ }^{5}$ The Claudio Cohen Department of Pediatric Intensive Care, The Edmond and Lily Safra Children's Hospital, Tel- Hashomer, Israel. ${ }^{6}$ Sackler Faculty of Medicine, Tel-Aviv University, Tel-Aviv, Israel. 
Received: 7 October 2017 Accepted: 22 May 2018

Published online: 04 June 2018

\section{References}

1. McKinnon PJ. ATM and the molecular pathogenesis of ataxia telangiectasia. Annu Rev Pathol. 2012;7:303-21. https://doi.org/10.1146/annurev-pathol011811-132509.

2. Shiloh Y, Ziv Y. The ATM protein kinase: regulating the cellular response to genotoxic stress, and more. Nat Rev Mol Cell Biol. 2013;14(4):197-210. https://doi.org/10.1038/nrm3546.

3. Nowak-Wegrzyn A, Crawford TO, Winkelstein JA, Carson KA, Lederman HM Immunodeficiency and infections in Ataxia telangiectasia. J Pediatr. 2004;144(4):505-11. https://doi.org/10.1016/j.jpeds.2003.12.046.

4. Crawford TO. Ataxia telangiectasia. Semin Pediatr Neurol. 1998;5(4):287-94. https://doi.org/10.1016/S1071-9091(98)80007-7.

5. Chopra C, Davies G, Taylor M, Anderson M, Bainbridge S, Tighe P, McDermott EM. Immune deficiency in Ataxia-telangiectasia: a longitudinal study of 44 patients. Clin Exp Immunol. 2014;176(2):275-82. https://doi.org/ 10.1111/cei.12262.

6. McConville CM, Stankovic T, Byrd PJ, McGuire GM, Yao QY, Lennox GG, Taylor MR. Mutations associated with variant phenotypes in ataxia-telangiectasia. Am J Hum Genet. 1996:59(2):320-30.

7. Staples ER, McDermott EM, Reiman A, Byrd PJ, Ritchie S, Taylor AM, Davies EG. Immunodeficiency in ataxia telangiectasia is correlated strongly with the presence of two null mutations in the ataxia telangiectasia mutated gene. Clin Exp Immunol. 2008;153(2):214-20. https://doi.org/10.1111/j.1365-2249. 2008.03684.x.

8. Kraus M, Lev A, Simon AJ, Levran I, Nissenkorn A, Levi YB, Berkun Y, Efrati O, Amariglio N, Rechavi G, Somech R. Disturbed B and T cell homeostasis and neogenesis in patients with ataxia telangiectasia. J Clin Immunol. 2014;34(5):561-72. https://doi.org/10.1007/s10875-014-0044-1.

9. Vacchio MS, Olaru A, Livak F, Hodes RJ. ATM deficiency impairs thymocyte maturation because of defective resolution of T cell receptor alpha locus coding end breaks. Proc Natl Acad Sci U S A. 2007;104(15):6323-8. https://doi.org/10.1073/pnas.0611222104.

10. Ersoy F, Berkel Al, Sanal O, Oktay H. Twenty-year follow-up of 160 patients with ataxia-telangiectasia. Turk J Pediatr. 1991;33(4):205-15.

11. Schroeder SA, Zielen S. Infections of the respiratory system in patients with ataxia-telangiectasia. Pediatr Pulmonol. 2014;49(4):389-99. https://doi.org/10.1002/ppul.22817.

12. Rothblum-Oviatt C, Wright J, Lefton-Greif MA, McGrath-Morrow SA, Crawford TO, Lederman HM. Ataxia telangiectasia: a review. Orphanet J Rare Dis. 2016:11(1):159. https://doi.org/10.1186/s13023-016-0543-7.

13. Ambrose M, Gatti RA. Pathogenesis of ataxia-telangiectasia: the next generation of ATM functions. Blood. 2013;121(20):4036-45. https://doi.org/ 10.1182/blood-2012-09-456897.

14. Weiss B, Krauthammer A, Soudack M, Lahad A, Sarouk I, Somech R, Heimer G, Ben-Zeev B, Nissenkorn A. Liver Disease in Pediatric Patients with Ataxia Telangiectasia: A Novel Report. J Pediatr Gastroenterol Nutr. 2016;62(4):550-5. https://doi.org/10.1097/MPG.0000000000001036.

15. Noordzij JG, Wulffraat NM, Haraldsson A, Meyts I, Van't Veer LJ, Hogervorst FB, Warris A, Weemaes CM. Ataxia-telangiectasia patients presenting with hyper-IgM syndrome. Arch Dis Child. 2009;94(6):448-9. https://doi.org/10.1136/ adc.2008.149351.

16. Aghamohammadi A, Imai K, Moazzami K, Abolhassani H, Tabatabaeiyan M, Parvaneh N, Nasiri Kalmarzi R, Nakagawa N, Oshima K, Ohara O, Nonoyama S, Rezaei N. Ataxia-telangiectasia in a patient presenting with hyper-immunoglobulin M syndrome. J Investig Allergol Clin Immunol. 2010;20(5):442-5.

17. Rawat A, Imai K, Suri D, Gupta A, Bhisikar S, Saikia B, Minz RW, Sehgal S, Singh S. Ataxia telangiectasia masquerading as hyper lgM syndrome. Indian J Pediatr. 2016;83(3):270-1. https://doi.org/10.1007/s12098-015-1852-x.

18. Tangsinmankong N, Wayne AS, Howenstine MS, Washington KR, Langston C, Gatti RA, Good RA, Nelson RP Jr. Lymphocytic interstitial pneumonitis, elevated I $\mathrm{M}$ concentration, and hepatosplenomegaly in ataxia-telangiectasia. J Pediatr. 2001;138(6):939-41. https://doi.org/10.1067/mpd.2001.113356

19. Azarsiz E, Karaca NE, Gunaydin NC, Gulez N, Ozturk C, Aksu G, Genel F, Kutukculer N. Do elevated serum lgM levels have to be included in probable diagnosis criteria of patients with ataxia-telangiectasia? Int J Immunopathol Pharmacol. 2014;27(3):421-7. https://doi.org/10.1177/ 039463201402700312.
20. van Os NJH, Jansen AFM, et al. Ataxia-telangiectasia: immunodeficiency and survival. Clin Immunol. 2017;178:45-55. https://doi.org/10.1016/j.clim.2017.01.009.

21. Winkelstein JA, Marino MC, Ochs H, Fuleihan R, Scholl PR, Geha R, Stiehm ER, Conley ME. The X-linked hyper-lgM syndrome: clinical and immunologic features of 79 patients. Medicine (Baltimore). 2003;82(6):373-84. https://doi.org/ 10.1097/01.md.0000100046.06009.b0.

22. de la Morena MT. Clinical Phenotypes of Hyper-lgM Syndromes. J Allergy Clin Immunol Pract. 2016;4(6):1023-36. https://doi.og/10.1016/j.jaip.2016.09.013.

23. Ammann AJ. Respiratory complications of ataxia-telangiectasia. N Engl J Med. 1969;281(18):1019.

24. Lev A, Simon AJ, Broides A, Levi J, Garty BZ, Rosenthal E, et al. Thymic function in MHC class II-deficient patients. J Allergy Clin Immunol. 2013;131(3):831-9. https://doi.org/10.1016/j.jaci.2012.10.040.

25. Lev A, Simon AJ, Bareket M, Bielorai B, Hutt D, Amariglio N, et al. The kinetics of early $T$ and $B$ cell immune recovery after bone marrow transplantation in RAG-2-deficient SCID patients. PLoS One. 2012;7(1) https://doi.org/10.1371/journal.pone.0030494.

26. Suarez $F$, et al. Incidence, presentation, and prognosis of malignancies in ataxia-telangiectasia: a report from the French national registry of primary immune deficiencies. J Clin Oncol. 2015;33(2):202-8. https://doi.org/10.1200/ JCO.2014.56.5101

27. McFarlin DE, Strober W, Waldmann TA. Ataxia Telangiectasia. Medicine (Baltimore). 1972;51:281-314

28. Ghiasy S, Parvaneh L, Azizi G, Sadri G, Zaki Dizaji M, Abolhassani H, Aghamohammadi A. The clinical significance of complete class switching defect in Ataxia telangiectasia patients. Expert Rev Clin Immunol. 2017;13(5):499-505. https://doi.org/10.1080/1744666X.2017.1292131.

29. Leven EA, et al. Hyper lgM syndrome: a report from the USIDNET registry. J Clin Immunol. 2016;36(5):490-501. https:/doi.org/10.1007/s10875-016-0291-4.

30. Paulino TL, Rafael MN, Hix S, Shigueoka DC, Ajzen SA, Kochi C, Suano-Souza FI, da Silva R, Costa-Carvalho BT, Sarni ROS. Is age a risk factor for liver disease and metabolic alterations in ataxia telangiectasia patients? Orphanet J Rare Dis. 2017;12:1-7. https://doi.org/10.1186/s13023-017-0689-y.

31. Reiman A, et al. Lymphoid tumors and breast cancer in ataxia telangiectasia; substantial protective effect of residual ATM kinase activity against childhood tumours. Br J Cancer. 2011;105(4):586-91. https://doi.org/10.1038/bjc.2011.266.

32. Mohammadinejad $P$, Abolhassani $H$, Aghamohammadi A, Pourhamdi S, Ghosh S, Sadeghi B, Nasiri Kalmarzi R, Durandy A, Borkhardt A. Class switch recombination process in ataxia telangiectasia patients with elevated serum levels of IgM. J Immunoassay Immunochem. 2015;36(1):16-26. https://doi.org/10.1080/15321819.2014.891525.
- fast, convenient online submission

- thorough peer review by experienced researchers in your field

- rapid publication on acceptance

- support for research data, including large and complex data types

- gold Open Access which fosters wider collaboration and increased citations

- maximum visibility for your research: over $100 \mathrm{M}$ website views per year

At BMC, research is always in progress.

Learn more biomedcentral.com/submissions 